\title{
DATA MINING SOSIAL KEMASYARAKATAN UNTUK KELENGKAPAN DASBOARD DESA
}

\author{
Zahir Zainuddin ${ }^{1}$, Hajar Hasan ${ }^{2}$, Yuyun ${ }^{3}$ \\ ${ }^{1}$ Departemen Teknik Informatika, Fakultas Teknik, Universitas Hasanuddin, Indonesia \\ ${ }^{2,3}$ Magister Sistem Komputer, STMIK Handayani Makassar, Indonesia \\ E-mail : 'Zainuddinzahir@gmail.com, ${ }^{2}$ Hasanhajar99@gmail.com, ${ }^{3}$ yuyunwabula@handayani.ac.id
}

(Naskah masuk : 17 Desember 2021, diterima untuk diterbitkan: 30 Desember 2021)

\begin{abstract}
Abstrak
Pemberdayaan masyarakat produktif merupakan upaya untuk memandirikan masyarakat, lewat perwujudan potensi kemampuan yang mereka miliki. Membangun sebuah desa yang lebih maju diperlukan langkah-langkah guna mendorong masyarakat untuk naik kelas. Tujuan penelitian ini adalah untuk mengelompokan penduduk desa dengan menggunakan pendekatan analisis kluster. Klusterisasi data penduduk pada Kota Tidore Kepulauan dengan menggunakan metode Rank Reciprocal dan Metode $K$-means dengan Kriteria sebanyak 38 dan Subkriteria sebanyak 134 yang berasal dari Dinas Sosial Kota Tidore Kepulauan. Hasil penelitian menunjukan bahwa hasil klusterisasi dari 81 kepala keluarga Desa Bukit Durian Kecamatan Oba Utara Kota Tidore Kepulauan yang di uji, hasil yang peroleh yaitu penduduk berada pada kluster pertama yang memiliki nilai 0,1 yang dapat diartikan sebagai kelompok penduduk yang tidak produktif atau kluster rendah sebanyak 1 kepala keluarga, kluster kedua yang memiliki nilai 0,29 yang dapat diartikan sebagai kelompok penduduk yang kurang produktif atau kluster sedang sebanyak 44 kepala keluarga, dan kluster ketiga yang memiliki nilai 0,50 yang dapat diartikan sebagai kelompok penduduk produktif atau kluster Tinggi sebanyak 36 kepala keluarga.
\end{abstract}

Kata kunci : Populasi, Analisis kluster, Metode Rank Reciprocal, Metode K-means

\section{COMMUNITY SOCIAL DATA MINING FOR VILLAGE DASHBOARD}

\begin{abstract}
Empowerment of productive communities is an effort to make the community independent, through the realization of the potential abilities they have. Building a village that is more advanced requires steps to encourage the community to advance to class. The purpose of this study was to group villagers using a cluster analysis approach. Clustering of population data in the City of Tidore Islands using the Rank Reciprocal method and the K-means method with 38 criteria and 134 sub-criteria originating from the Social Service of the Tidore Islands City. The results showed that the results of clustering of 81 family heads in Bukit Durian Village, North Oba District, Tidore Islands City were tested, the results obtained were that the population was in the first cluster which had a value of 0.1 which could be interpreted as a group of people who were not productive or low cluster. as many as 1 family head, the second cluster which has a value of 0.29 which can be interpreted as a group of people who are less productive or a moderate cluster of 44 households, and the third cluster which has a value of 0.50 which can be interpreted as a productive population group or a high cluster of as many as 1 household. 36 heads of families.
\end{abstract}

Keyword : Population, Cluster Analysis, Method Reciprocal Rank, Method K-means

\section{PENDAHULUAN}

Dalam kerangka otonomi daerah, salah satu komponen penting adalah pengembangan wilayah pedesaan. Didalam Peraturan Pemerintah No. 72 Tahun 2005 bahwa desa diberikan kesempatan untuk mengatur dan mengurus rumah tangganya sendiri yakni dengan memperhatikan prinsip-prinsip demokrasi, peran serta masyarakat, pemerataan, keadilan, serta memperhatikan potensi dan keanekaragaman daerah [1], [2]. Pembangunan pedesaan seharusnya mengarah pada peningkatan kesejahteraan masyarakat melalui pember-dayaan masyarakat desa.Pemberdayaan masyarakat berupaya untuk meningkatkan kualitas sumber daya manusia (SDM) terutama dalam membentuk dan merubah perilaku masyarakat untuk mencapai kehidupan yang lebih baik dan taraf hidup yang lebih berkualitas[3]. Salah datu komponen penting dalam pengembangan desa adalah pemanfaatan dashboar. 
Dashboard adalah sebuah tampilan panel yang di buat oleh sebuah software komputer dengan tujuan menampilkan informasi yang mudah dibaca. Sehingga dengan demikian pemanfaatan dashboard desa dapat memudahkan mengidentifikasi masyarakat yang produktif dan tidak[4]. Produktif adalah sesuatu hal yang bisa menghasilkan atau mendatangkan keuntungan secara besar atau banyak. Jika menghasilkan hanya satu atau dalam jumlah yang relatif sedikit, maka sesuatu hal tersebut belum dapat dikatakan produktif. Masyarakat produktif dapat diartikan sebagai masyarakat yang mampu mengelola sumber daya disekitarnya baik itu barang primer, barang sekunder, maupun barang tersier ataupun barang lain yang bisa dipersamakan dengan itu[5].

Pemberdayaan masyarakat produktif merupakan upaya untuk memandirikan masyarakat, lewat perwujudan potensi kemampuan yang mereka miliki. Membagun sebuah desa yang lebih maju diperlukan langkah-langka guna mendorong masyarakat untuk naik kelas. Seperti dengan meyediakan lapangan kerja yang akan membuat masyarakat bawah lebih produktif[6].

Wilayah Kota Tidore Kepulauan yang terdiri dari 8 kecamatan,40 Kelurahan, dan 49 Desa dengan luas wilayah $1.645,73 \mathrm{~km}^{2}$ dan jumlah penduduk 101.414 jiwa (2019). Data yang diperoleh dari Badan Pusat Statistik Kota Tidore Kepulauan Tahun 2019 angka Kemiskinan berjumlah 6.186 atau sekitar $6,10 \%$. Pemerintah telah melaksanakan program penanggulangan kemiskinan melalui berbagai upaya seperti meningkatkan kesejahteraan sosial ekonomi masyarakat miskin, penguatan kelembagaan sosial ekonomi masyarakat serta melaksanakan percepatan pembangunan desa. Program-program tersebut kurang berhasil dalam implementasinya. Melalui penelitian ini penulis melakukan pendekatan dengan mengelompokan masyarakat tidak produktif, kurang produktif dan produktif untuk mengukur tingkat keberhasilan masyarakat desa. produktifitas masyarakat akan diimplementasikan pada proses perhitungan data mining dengan menggunakan metode Rank Reciprocal (RR) dengan kriteria sebanyak 38 dan jumlah subkriteria adalah 134, setiap kriteria terdiri dari subkriteria yang digunakan sebagai parameter penilaian terhadap setiap kepala keluarga.

Dengan mengetahui produktifitas masyarakat pada kluster rendah, sedang dan tinggi, perlu pemanfaatan dasboard desa. Penggunaan dasbor dalam penelitian ini untuk menampilkan informasi tentang produktifitas pada masyarakat desa menggunakan algoritma clustering, salah satunya dengan metode K-Means. Dari hasil pembobotan kriteria dapat diusulkan dengan metode pengelompokan kriteria yang berpengaruh untuk mendapatkan cluster masyarakat. Hasil Akhir (output) dapat dijadikan acuan untuk meningkatkan produktivitas penduduk desa kedepan.
Adapun penelitian yang terkait yaitu analisis pembobotan kriteria yaitu penentuan bobot multikriteria dalam pengambilan keputusan menjadi suatu kesulitan bagi pengambil keputusan, penentuan bobot diperlukan untuk melakukan evaluasi kriteria. Salah satu cara penentuan bobot adalah dengan menentukan urutan prioritas kriteria dan menggunakan surrogate weight (bobot pengganti) untuk menentukan bobot sesuai dengan jumlah kriteria yang digunakan. Dan hasilnya untuk menentukan bobot kriteria yaitu $R S, R R, R O C$ dan $E W$ serta melakukan perankingan menggunakan $S A W$, sehingga menghasilkan perankingan dapat dilakukan perbandingan hasil alternatif terbaik dengan nilai bobot yang dihasilkan setiap metode[7]. sedangkan penelitian terkait untuk kluster yaitu pengelompokan masyarakat miskin (S Ramadani, dkk. Penelitian ini menggali data masyarakat miskin kota binjai untuk mendapatkan informasi baru dengan mengelompokan data-data kemiskinan menggunakan metode data mining $\mathrm{k}$-means clustering dengan menggunakan jarak kedekatan Manhattan City dan Euclidean. Program tersebut akan diimplementasikan untuk mengelompokan masyarakat miskin di Kota Binjai dan hasilnya untuk mendapatkan informasi baru dengan mengelompokkan data-data kemiskinan menggunakan metode data mining k-means clustering dengan menggunakan jarak kedekatan Manhattan City dan Euclidean, sehingga dapat diketahui kelompok variabel-variabel yang sangat berpengaruh pada masyarakat miskin[8]. Pada penelitian ini kami menerapkan 2 pendekatan yaitu Metode Rank Reciprocal untuk pembobotan kriteria dan Metode $K$-means untuk mengkluster masyarakat yang produktif, kurang produktif dan tidak produktif

\section{METODE PENELITIAN}

Data yang dipergunakan dalam penelitian adalah data primer yang bersumber dari Dinas Sosial Kota Tidore Kepulauan, dimana terdapat data penduduk desa dan kemudian dikelompokan berdasarkan kriteria dan subkriteria menggunakan analisis kluster.

Adapun perancangan dari sistem ini dimulai dengan penginputan data penduduk berdasarkan kriteria sebanyak 38 dan subkriteria sebanyak 134, setiap kriteria terdiri dari subkriteria yang digunakan sebagai parameter penilaian terhadap setiap kepala keluarga. Proses penilaian kriteria dan subkriteria menggunakan Metode Rank Reciprocal dan proses Pengelompokan data digunakan metode $K$-means.

Metode analisis data yang di gunakan pada penelitian ini adalah 2 metode yakni yang pertama adalah metode Rank Reciprocal (RR), dimana merupakan metode dalam menentukan nilai bobot. Rank Reciprocal bekerja dengan menitik beratkan bahwa kriteria pertama lebih penting dibanding kriteria kedua, kriteria kedua lebih penting dibanding kriteria ke tiga, begitu selanjutnya. Perhitungan bobot dengan metode rank reciprocal diperoleh dari 
normalisir timbal-balik rangking kriteria[7]. Metode $R R$ dapat digambarkan melalu penulisan rumus yang dijadikan sebagai petunjuk dalam penggunaanya adalah sebagai berikut :

$$
W j=\frac{1 / r j}{\sum(1 / r k)}
$$

\section{Keterangan}

$$
\begin{aligned}
& \mathbf{w}_{\mathbf{j}}=\text { Nilai Bobot (kriteria/subkriteria) } \\
& \mathbf{r}_{\mathbf{j}} \quad=\text { Nilai urutan rangking } \\
& \text { kriteria/subkriteria). } \\
& \text { rk = Jumlah total } \\
& \text { tujuan(kriteria/subkriteria). }
\end{aligned}
$$

Data yang akan digunakan untuk menerapkan metode RR adalah data kriteria sebanyak 38 dan jumlah data subkriteria adalah 34 setiap kriteria terdiri dari subkriteria yang digunakan sebagai parameter penilaian terhadap setiap kepala keluarga.

Sedangkan metode analisis data yang kedua adalah algoritma $K$-means, dimana $K$-means merupakan salah satu metode data clustering non hirarki yang berusaha mempartisi data ke dalam cluster/kelompok sehingga data yang memiliki karakteristik sama dikelompokkan ke dalam satu cluster yang sama[9], [10].

Algoritma $K$-means merupakan algoritma yang membutuhkan parameter input sebanyak $\mathrm{k}$ dan membagi sekumpulan $\mathrm{n}$ objek kedalam $\mathrm{k}$ cluster sehingga tingkat kemiripan antar anggota dalam satu cluster tinggi sedangkan tingkat kemiripan dengan anggota pada cluster lain sangat rendah[11]. Kemiripan anggota terhadap cluster diukur dengan kedekatan objek terhadap nilai mean pada cluster atau dapat disebut sebagai centroid cluster atau pusat massa.

Proses algoritma K-Means yaitu Pilih secara acak objek sebanyak k, objek-objek tersebut akan direpresentasikan sebagai mean pada cluster, Untuk setiap objek dimasukan kedalam cluster yang tingkat kemiripan objek terhadap cluster tersebut tinggi. Tingkat kemiripan ditentukan dengan jarak objek terhadap mean atau centroid cluster tersebut, Hitung nilai centroid yang baru pada masing-masing cluster. Proses tersebut diulang hingga anggota pada kumpulan cluster tersebut tidak berubah[12].

Langkah-langkah dari algoritma K-Means ditunjukkan pada Gambar 1.

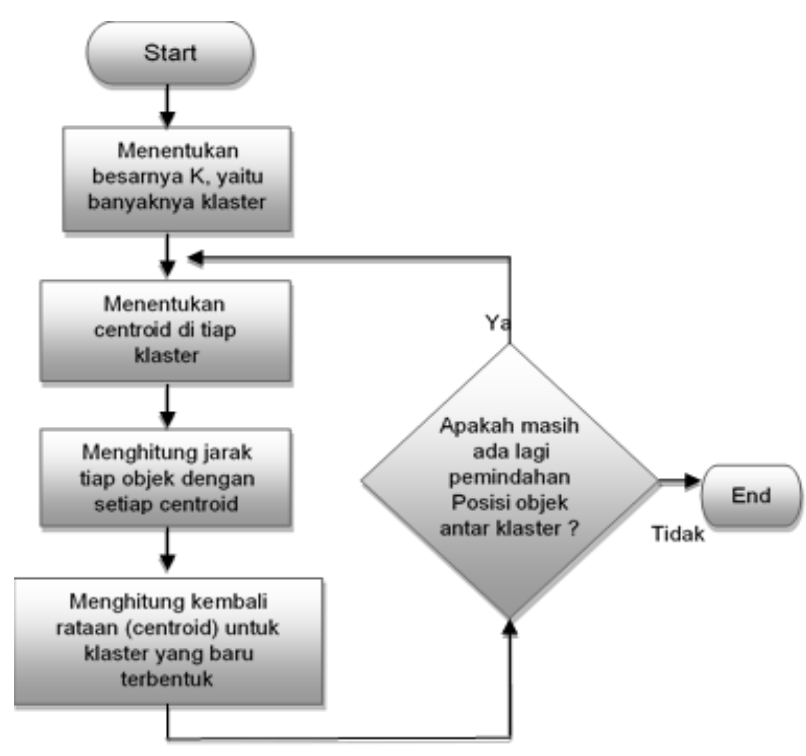

Gambar 1. Alur algoritma K-Means

Algoritma $K$-means dilakukan cara berikut hingga ditemukan hasil iterasi yang stabil :

a. Menentukan data centroid, ditentukan bahwa centroid pertama adalah $\mathrm{n}$ data pertama dari datadata yang akan di-klaster.

b. Menghitung jarak antara centroid dengan masingmasing data.

c. Mengelompokkan data berdasarkan jarak minimum.

d. Jika penempatan data sudah sama dengan sebelumnya, maka stop. Jika tidak, kembali ke cara yang ke-2 [13].

\section{HASIL DAN PEMBAHASAN}

Berdasarkan dari metode rancangan, maka didapatkan hasil dari penelitian yaitu suatu aplikasi Dasboard desa yang memberikan informasi tentang mengkluster penduduk yang tidak produktif (kluster rendah), kurang produktif (kluster sedang) dan produktif (kluster tinggi).

Adapun tahapan penerapan metode $R R$ untuk memperoleh nilai bobot terhadap kriteria dan subkriteria adalah berdasarkan data kriteria yang terlebih dahulu di tentukan nilai prioritas yang ditandai berdasarkan rangking, dalam hal ini kriteria yang dianggap prioritas atau lebih penting maka akan lebih dulu di masukan ke dalam sistem. Untuk mendapatkan nilai bobot terhadap kriteria di lakukan dengan menerapkan rumus $R R$, jumlah kriteria yang akan di proses yaitu sebanyak 38 . Proses perhitungan dapat di lihat pada tabel 1 . 
Tabel 1.Proses penentuan nilai bobot terhadap kriteria

\begin{tabular}{|c|c|c|c|}
\hline \multicolumn{4}{|c|}{ Rank Reciprocal } \\
\hline RANK & Rumus & Nilai (P) & $\begin{array}{c}\text { Hasil }= \\
(\mathbf{W j})\end{array}$ \\
\hline 38 & $(0+(1 / 38)) / 38$ & 0,026315 & 0,000692 \\
\hline 37 & $(0,026315+(1 / 37)) / 38$ & 0,053342 & 0,001403 \\
\hline 36 & $(0,053342+(1 / 36)) / 38$ & 0,081120 & 0,002134 \\
\hline 35 & $(0,081120+(1 / 35)) / 38$ & 0,109692 & 0,002886 \\
\hline 34 & $(0,109692+(1 / 34)) / 38$ & 0,139103 & 0,003660 \\
\hline 33 & $(0,139103+(1 / 33)) / 38$ & 0,169406 & 0,004458 \\
\hline 32 & $(0,169406+(1 / 32)) / 38$ & 0,200656 & 0,005280 \\
\hline 31 & $(0,200656+(1 / 31)) / 38$ & 0,232914 & 0,006129 \\
\hline 30 & $(0,232914+(1 / 30)) / 38$ & 0,266248 & 0,007006 \\
\hline 29 & $(0,266248+(1 / 29)) / 38$ & 0,300730 & 0,007913 \\
\hline 28 & $(0,300730+(1 / 28)) / 38$ & 0,336445 & 0,008853 \\
\hline 27 & $(0,336445+(1 / 27)) / 38$ & 0,373482 & 0,009828 \\
\hline 26 & $(0,373482+(1 / 26)) / 38$ & 0,411943 & 0,010840 \\
\hline 25 & $(0,411943+(1 / 25)) / 38$ & 0,451943 & 0,011893 \\
\hline 24 & $(0,451943+(1 / 24)) / 38$ & 0,493610 & 0,012989 \\
\hline 23 & $(0,493610+(1 / 23)) / 38$ & 0,537088 & 0,014133 \\
\hline 22 & $(0,537088+(1 / 22)) / 38$ & 0,582543 & 0,015330 \\
\hline 21 & $(0,582543+(1 / 21)) / 38$ & 0,630162 & 0,016583 \\
\hline 20 & $(0,630162+(1 / 20)) / 38$ & 0,680162 & 0,017899 \\
\hline 19 & $(0,680162+(1 / 19)) / 38$ & 0,732793 & 0,019284 \\
\hline 18 & $(0,732793+(1 / 18)) / 38$ & 0,788349 & 0,020746 \\
\hline 17 & $(0,788349+(1 / 17)) / 38$ & 0,847173 & 0,022294 \\
\hline 16 & $(0,847173+(1 / 16)) / 38$ & 0,909673 & 0,023938 \\
\hline 15 & $(0,909673+(1 / 15)) / 38$ & 0,976339 & 0,025693 \\
\hline 14 & $(0,976339+(1 / 14)) / 38$ & 1,047768 & 0,027572 \\
\hline 13 & $(1,047768+(1 / 13)) / 38$ & 1,124691 & 0,029597 \\
\hline 12 & $(1,124691+(1 / 12)) / 38$ & 1,208024 & 0,031790 \\
\hline 11 & $(1,208024+(1 / 11)) / 38$ & 1,298933 & 0,034182 \\
\hline 10 & $(1,298933+(1 / 10)) / 38$ & 1,398933 & 0,036814 \\
\hline 9 & $(1,398933+(1 / 9)) / 38$ & 1,510044 & 0,039738 \\
\hline 8 & $(1,510044+(1 / 8)) / 38$ & 1,635044 & 0,043027 \\
\hline 7 & $(1,635044+(1 / 7)) / 38$ & 1,777902 & 0,046786 \\
\hline 6 & $(1,777902+(1 / 6)) / 38$ & 1,944568 & 0,051172 \\
\hline 5 & $(1,944568+(1 / 5)) / 38$ & 2,144568 & 0,056436 \\
\hline 4 & $(2,144568+(1 / 4)) / 38$ & 2,394568 & 0,063014 \\
\hline 3 & $(2,394568+(1 / 3)) / 38$ & 2,727902 & 0,071786 \\
\hline 2 & $(2,727902+(1 / 2)) / 38$ & 3,227902 & 0,084944 \\
\hline 1 & $(3,227902+(1 / 1)) / 38$ & 4,227902 & 0,11126 \\
\hline & TOTAL & & 1,0000 \\
\hline
\end{tabular}

Untuk mendapatkan nilai bobot subkriteria dilakukan juga dengan menggunakan rumus $R R$, Jumlah subkriteria yang akan diproses yaitu sebanyak 134. Terdapat variasi terhadap jumlah subkriteria yang digunakan, karena setiap kriteria memiliki subkriteria yang berbeda, sehinga penentukan nilai $r k$ tidak dapat digunakan secara universal.

Hasil perkalian bobot kriteria dan subkriteria untuk setiap penduduk dijumlahkan dan akan menjadi nilai inputan pada proses klusterisasi menggunakan metode $K$-Means. Contoh hasil penilaain yang telah dilakukan pada salah satu kepala keluarga yanga ada di Desa Bukit Durian Kecamatan Oba Utara Kota Tidore Kepulauan dapat dilihat pada tabel 2 :

Tabel 2. Penilaian bobot kriteria dan subkriteria satu kepala keluaraga.

\begin{tabular}{|c|c|c|c|c|c|}
\hline \multicolumn{6}{|c|}{ NIK: 8201030703081121 } \\
\hline \multicolumn{6}{|c|}{ Nama: Apner Uka } \\
\hline \multicolumn{6}{|c|}{ Total Nilai :0,3185623 } \\
\hline No & Kriteria & $\begin{array}{c}\text { Sub } \\
\text { Kriteri } \\
\mathbf{a}\end{array}$ & $\begin{array}{c}\text { N- } \\
\text { Kriteri } \\
\mathbf{a}\end{array}$ & $\begin{array}{c}\text { N-Sub } \\
\text { Kriteri } \\
\quad \mathbf{a} \\
\end{array}$ & $\begin{array}{l}\text { Wk * } \\
\text { Wsk }\end{array}$ \\
\hline 1 & $\begin{array}{l}\text { status } \\
\text { kesejahtera } \\
\text { an (desil) }\end{array}$ & $\begin{array}{l}\text { Rumah } \\
\text { tangga } \\
\text { kondisi } \\
\text { kesejah } \\
\text { teraan } \\
11 \% \text { - } \\
20 \% \\
\text { terenda }\end{array}$ & $\begin{array}{l}0,1112 \\
61\end{array}$ & $\begin{array}{c}0,2777 \\
78\end{array}$ & 0,030 \\
\hline
\end{tabular}

Status

kepemilika

2 n bangunan

tempat

tinggal

Status

kepemilika

3 n lahan

tempat

tinggal

Jenis lantai

4 terluas

Jenis

5 dinding

terluas

Jenis atap

terluas

Kualitas

7 dinding

terluas

Kualitas

atap terluas

Beba

$0,0849 \quad 0,1566$

0,013

sewa $\quad 45 \quad 67$

Sumber air

Milik $\quad 0,0717 \quad 0,5208$

0,037

sendiri

87

Paket/v

inil/per

0,0630

0,1428

0,009

Tembo

$\mathrm{k}$

Genten

g tanah

liat

Bagus/

kualita

s tinggi

Bagus/

kualita

s tinggi

Sumur

minum

bor/po

mpa

Cara

10 memperole

Tidak

membe

li

minum

Penggunaa

1 n fasilitas

buang air

Sendiri

15

97

(1)

0,0564

36

0,3704

0,020

$0,0511 \quad 0,1095$

$73 \quad 63$

0,005

$0,0467 \quad 0,0520$

$87 \quad 83$

0,035

$0,0430 \quad 0,0520$

$\begin{array}{lcl}28 & 83 & 0,032\end{array}$

$0,0397 \quad 0,0849$

$\begin{array}{lll}38 & 90 & 0,003\end{array}$

besar

12 Jenis kloset

Cempl

ung/cu

bluk

Tempat

Kolam/

13 pembuanga sawah/

$\mathrm{n}$ akhir tinja sungai/
$0,0368 \quad 0,1111 \quad 0,004$

$14 \quad 1$

$0,0341 \quad 0,5208$

0,017

$0,0317 \quad 0,1458$

0,004

$0,0295 \quad 0,1027$

$97 \quad 78$ 
danau/l

aut

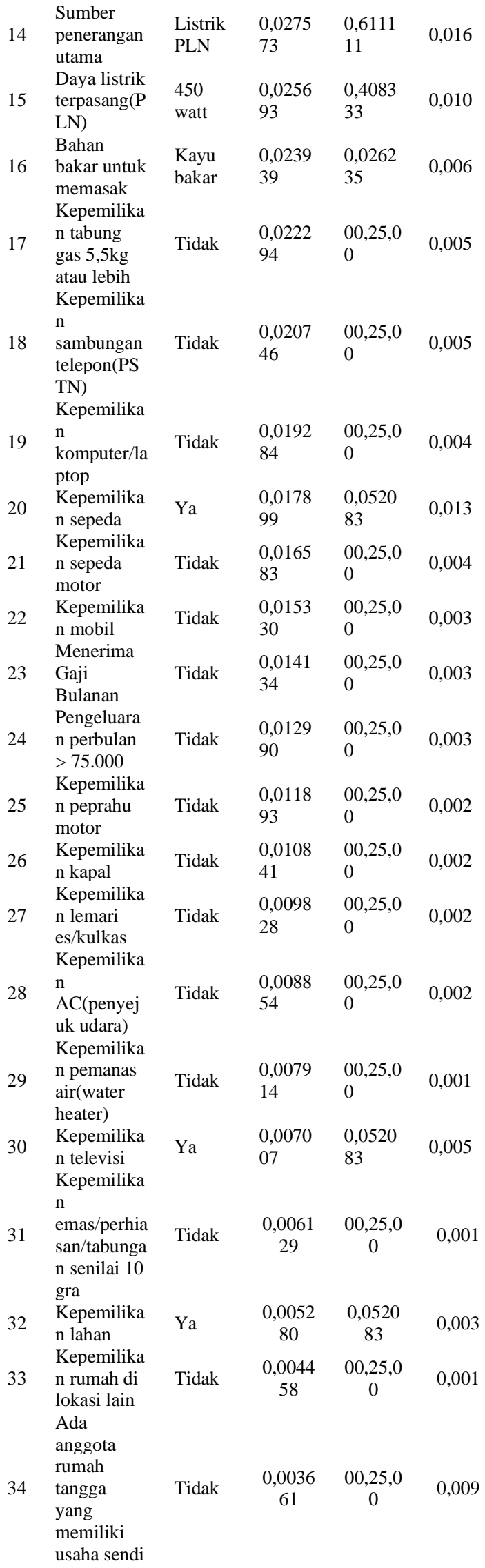

\begin{tabular}{clcccc}
35 & $\begin{array}{l}\text { Memiliki } \\
\text { kks/kps }\end{array}$ & Ya & 0,0028 & 0,0520 & 0,002 \\
& $\begin{array}{l}\text { Peserta } \\
\text { program } \\
\text { pkh }\end{array}$ & Ya & 0,0021 & 0,0520 & 0,001 \\
& $\begin{array}{l}\text { Peserta } \\
\text { program } \\
\text { raskin }\end{array}$ & Tidak & 0,0014 & $00,25,0$ & 0,003 \\
& $\begin{array}{l}\text { Peserta } \\
\text { program } \\
\text { kur }\end{array}$ & Tidak & 0,0006 & $00,25,0$ & 0,001 \\
\hline
\end{tabular}

Dari hasil analisi diatas kemudian di implementasikan dengan 81 (Delapan puluh satu) kepala keluarga yang berada di Desa Bukit Durian Kecamatan Oba Utara Kota Tidore Kepulauan kedalam sistem. Selanjutnya dilakukan proses klusterisasi dengan metode K-means, Algoritma $K$ means merupakan algoritma yang membutuhkan parameter input sebanyak $\mathrm{k}$ dan membagi sekumpulan $\mathrm{n}$ objek kedalam $k$ cluster sehingga tingkat kemiripan antar anggota dalam satu cluster tinggi sedangkan tingkat kemiripan dengan anggota pada cluster lain sangat rendah[14]. Kemiripan anggota terhadap cluster diukur dengan kedekatan objek terhadap nilai mean pada cluster atau dapat disebut sebagai centroid cluster. Jarak yang terpendek antara centroid dengan dokumen menentukan posisi cluster suatu dokumen. Misalnya dokumen A mempunyai jarak yang paling pendek ke centroid 1 dibanding ke yang lain, maka dokumen A masuk ke group 1[15].

Adapun tahapan penerapan metode K-means pada sistem telah dibangun adalah dibutuhkan nilai yang berguna sebagai data awal. Nilai inputan yang akan diproses yaitu hasil penilaian terhadap penduduk berdasarkan kriteria dan subkriteria yang diolah menggunakan metode Rank Reciprocal (RR). Data centroid dibagi menjadi 3 yaitu : kluster pertama memiliki nilai 0,1 yang dapat diartikan sebagai kelompok penduduk yang tidak produktif atau kluster rendah, kluster kedua memiliki nilai 0,29 yang dapat diartikan sebagai kelompok penduduk yang kurang produktif atau kluster sedang, kluster ketiga memiliki nilai 0,5 yang dapat diartikan sebagai kelompok penduduk produktif atau kluster tinggi. Melakukan pengukuran jarak data record/ nilai penduduk terhadap setiap centroid. Berdasarkan hasil pengukur jarak maka akan dipilih jarak yang paling kecil dengan centroid dan menghasilkan pengelompokan penduduk berdasarkan kluster.

Hasil klusterisasi menggunakan metode $K$ means dapat diimplementasikan ke dalam bahasa pemrograman agar metode yang digunakan dapat bekerja secara dinamis. Hasil klusterisasi 81 kepala keluarga Desa Bukit Durian Kecamatan Oba Utara Kota Tidore Kepulauan yang diuji, hasil yang diperoleh yaitu penduduk berada pada kluster pertama yang memiliki nilai 0,1 yang dapat diartikan sebagai kelompok penduduk yang tidak produktif atau kluster rendah dengan kriteria yang terdiri dari kode C1 Status Kesejahteraan(desil) dengan 
subkriteria rumah tangga/individu kesejahteraan 21\%-30\% terendah, kode C23 Menerima gaji bulanan dengan subkriteria pada pilihan tidak, kode C34 Ada anggota rumah tangga yang memiliki usaha sendiri dengan subkriteria tidak, kode C35 memiliki KKS/KPS dengan subkriteria pada pilihan pada pilihan ya, kode C36 peserta program PKH dengan subkriteria pada pilihan ya sebanyak 1 Kepala keluarga.

Kluster kedua yang memiliki nilai 0,29 yang dapat diartikan sebagai kelompok penduduk yang kurang produktif atau kluster sedang dengan kriteria yang mempengaruhi tingkat produktivitas terdiri dari kode C1 Status Kesejahteraan dengan subkriteria rumah tangga/individu kesejahteraan 11\%-20\% terendah, Kode C23 Menerima gaji bulanan dengan subkriteria pada pilihan tidak, Kode C34 Ada anggota rumah tangga yang memiliki usaha sendiri dengan subkriteria tidak, kode C35 memiliki KKS/KPS dengan subkriteria pada pilihan ya, kode C36 peserta program $\mathrm{PKH}$ dengan subkriteria pada pilihan ya sebanyak 44 kepala keluarga.

Dan kluster ketiga yang memiliki nilai 0,50 yang dapat diartikan sebagai kelompok penduduk produktif atau kluster Tinggi dengan kriteria yang mempengaruhi tingkat produktivitas terdiri dari kode C1 Status Kesejahteraan dengan subkriteria rumah tangga/individu kesejahteraan $10 \%$ terendah,Kode C23 Menerima gaji bulanan dengan subkriteria pada pilihan ya, kode C34 Ada anggota rumah tangga yang memiliki usaha sendiri dengan subkriteria ya, kode C35 memiliki KKS/KPS dengan subkriteria pada pilihan tidak, kode $\mathrm{C} 36$ peserta program $\mathrm{PKH}$ dengan subkriteria pada pilihan tidak sebanyak 36 kepala keluarga, berdasarkan hasil tersebut dapat dijadikan acuan bahwa masyarakat pada daerah yang diuji ratarata memiliki status produktif normal. Selanjutnya akan dilakukan pengujian akurasi dalam bentuk manual.

Penelitian ini memperlihatkan ouput berupa aplikasi dashboard desa hasil klusterisasi penduduk dengan klusterisasi menggunakan metode $K$-means yang dapat diimplementasikan ke dalam bahasa pemrograman agar metode yang digunakan dapat bekerja secara dinamis.

\section{KESIMPULAN}

Berdasarkan hasil penelitian dan pembahasan yang telah diuraikan, dapat ditarik kesimpulan bahwa dari hasil penilaian dengan penerapan metode Rank Reciprocal $(R R)$ adalah data kriteria sebanyak 38 dan jumlah data subkriteria adalah 134 setiap kriteria terdiri dari subkriteria yang digunakan sebagai parameter penilaian terhadap setiap kepala keluarga. Proses perhitungan bobot kriteria dan subkriteria pilihan akan menjadi skala prioritas dengan bobot tertinggi yang mempengaruhi tinggkat produktifitas penduduk adalah status kesejahteraan (desil) dengan subkriteria (rumah tangga/individu kesejahteraan terendah). Kriteria dengan bobot terendah adalah peserta program kur dengan subkriteria pilihan (Ya/Tidak). Hasil penelitian menunjukkan bahwa Berdasarkan parameter penilaian pada 81 data penduduk yang diuji, hasil yang diperoleh yaitu penduduk berada pada kluster rendah(tidak produktif) dengan memiliki nilai 0,1 sebanyak 1 kepala keluarga, kluster sedang (kurang produktif) dengan memiliki nilai 0,29 sebanyak 41 kepala keluarga dan kluster tinggi (produktif) dengan memiliki nilai 0,50 sebanyak 36 kepala keluarga, berdasarkan hasil tersebut dapat dijadikan acuan bahwa masyarakat pada daerah yang diuji rata-rata memiliki status produktif normal.

\section{DAFTAR PUSTAKA}

[1] A. Mustanir, K. Sellang, and A. Ali. 2019. "Peranan Aparatur Pemerintah Desa dan Partisipasi Masyarakat Dalam Musyawarah Perencanaan Pembangunan Di Desa Tonrongnge Kecamatan Baranti ...," JCG J. Clean ..., no. March.

[2] E. Panjaitan, R. Dewi, and N. Angelia. 2019. "Peranan Pemerintah Desa dalam Meningkatkan Kualitas Pelayanan Administrasi kepada Masyarakat," Perspektif, vol. 8, no. 1, p. 32.

[3] U. Andini. 2017. "Pemberdayaan Ekonomi Masyarakat Dari Desa Tertinggal Menuju Desa Tidak Tertinggal (Studi Di Desa Muktiharjo Kecamatan Margorejo Kabupaten Pati)," J. Adm. Publik Mhs. Univ. Brawijaya, vol. 3, no. 1, pp. 7-11.

[4] L. M. R, W. Wikusna, M. Kom, and P. Aji. 2018. “Aplikasi Dashboard Untuk Monitoring Dan Controlling Tumbuh Kembang Anak , Pemberian Imunisasi Dan Vitamin a Untuk Desa Se- Kecamatan Bojongsoang the Dashboard Application for Monitoring and Controlling Child Growth , Giving Immunization and Vitamin a in B," vol. 4, no. 3, pp. 1408-1415.

[5] N. Purwanto and C. Rofiah. 2017. "Pemberdayaan Usaha Ekonomi Produktif Bagi Masyarakat Di Kecamatan Ploso Kabupaten Jombang," Comvice J. community Serv., vol. 1, no. 1, pp. 29-32.

[6] D. I. Jember, S. A. Mustaniroh, A. Shinta, J. M. Maligan, and N. Azizah. 2017. "Salah satu sasaran utama dari setiap usaha pertanian termasuk agroforestri adalah produksi yang berkelanjutan ( sustainable ) yang dicirikan oleh stabilitas produksi dalam jangka panjang ( Widianto et al ., 2003 ). Tujuan dan manfaat umum kegiatan pengabd," pp. 147-151.

[7] I. G. I. Sudipa and K. S. Aryati. 2019. "Pendekatan Penentuan Bobot dengan Surrogate Weighting Procedures untuk Metode Simple Additive Weighting dalam Pengambilan Keputusan Multikriteria," vol. 3, no. 3, pp. 113- 
121.

[8] S. Utara. 2019. "Metode K-Means Untuk Pengelompokan Masyarakat Miskin Dengan Menggunakan Jarak Kedekatan Manhattan City Dan Euclidean ( Studi Kasus Kota Binjai ),”.

[9] P. Alkhairi and A. P. Windarto. 2019. "Penerapan K-Means Cluster Pada Daerah Potensi Pertanian Karet Produktif di Sumatera Utara," pp. 762-767.

[10] R. Sundari, S. Solikhun, E. Irawan, and E. Satria. 2019. "Penerapan Algoritma K-Means Clustering dalam Mengelompokkan Jumlah Posyandu Aktif Berdasarkan Provinsi," Pros. Semin. Nas. Ris. Inf. Sci., vol. 1, no. September, p. 631 .

[11] Hablum. R. J., A. Khairan dan Rosihan. 2019 "Clustering Hasil Tangkap Ikan Di Pelabuhan Perikanan Nusantara (PPN) Ternate Menggunakan Algoritma K-Means," JIKO (Jurnal Inform. dan Komputer), vol. 2, no. 1, pp. 26-33.

[12] I. Parlina, A. P. Windarto, A. Wanto, and M. R. Lubis. 2018. "Memanfaatkan Algoritma KMeans Dalam Menentukan Pegawai Yang Layak Mengikuti Asessment Center," Memanfaatkan Algoritm. K-Means Dalam Menentukan Pegawai Yang Layak Mengikuti Asessment Cent. Untuk Clust. Progr. Sdp, vol. 3, no. 1, pp. 87-93.

[13] S. Suryadi. 2018. "Penerapan Metode Clustering K-means Untuk Pengelompokan Kelulusan Mahasiswa. "vol. 6, no. 1, pp. 52-72.

[14] M. L. Sibuea and A. Safta. 2017. "Pemetaan Siswa Berprestasi Menggunakan Metode KMeans Clustring," Jurteksi, vol. 4, no. 1, pp. 8592.

[15] R. Rosmini, A. Fadlil, and S. Sunardi. 2018. "Implementasi Metode K-Means Dalam Pemetaan Kelompok Mahasiswa Melalui Data Aktivitas Kuliah," It J. Res. Dev., vol. 3, no. 1, pp. 22-31, 2018. 